\title{
Top Management Team Diversity, Quality Decisions and Organizational Performance in the Service Industry
}

\author{
Dr Zachary B Awino \\ Senior Lecturer, Department Of Business Administration, School of Business, University Of Nairobi \\ P.o Box 30197-00100 Nairobi, Kenya \\ Tel: 254-720-565-317 E-mail: zb.awino@uonbi.ac.ke
}

Received: November 23, 2012

doi:10.5430/jms.v4n1p113

\author{
Accepted: December 22, $2012 \quad$ Online Published: February 15, 2013 \\ URL: http://dx.doi.org/10.5430/jms.v4n1p113
}

\begin{abstract}
Some past studies have found that the characteristics of the Top Management Team influence the performance of organizations while others have found that they do not. This study, which is founded on the Upper Echelon Theory, investigated the relationship between TMT diversity, quality decisions and organization performance. The study sought to find out the effect of TMT diversity and quality decisions in the performance of commercial banks in Kenya. The study found that quality decisions had a significant effect on the internal business processes and learning and growth perspectives of the balanced scorecard. The study sought to find the intervening effect of the quality decisions and the moderating effect of involvement culture and diversity management strategies. The study found that the two moderating variables had a significant effect on the relationship between TMT diversity and quality decisions and TMT diversity and organization performance.
\end{abstract}

Keywords: Diversity, Top management team, Quality decisions, Organizational performance

\section{Introduction}

As organizations increasingly operate in a multinational and multicultural context, understanding how diversity in the composition of organization group affects outcomes such as satisfaction, creativity, turnover and performance is of increasing importance (Johnston \& Packer, 1987). Top Management Team and their importance as potential determinants of organization performance continue to be a focus of strategic management researchers (Carson et al., 2004). Morison (1992) argued that organizations need to become more diverse with the respect to their employees' characteristics to match the increased diversity of backgrounds represented in their markets. The potential cognitive benefits of having a heterogeneous group stem from the argument on the impact of diversity on creativity (Hoffman and Maier, 1961) and requisite variety.

Researchers have argued that in service industries like banks where competition is stiff and new players enter easily, there is a constant need to think strategically (Willie et al., 1997). According to Milliken and Martins (1996), diverse groups may make higher quality decisions. Organizational scholars (Cox et al., 1991) have illustrated that demographic characteristics of TMT have the potential to result in strategic decision making, greater creativity, more innovation and the ability to reach more and different types of customers, which is important in the banking sector. Proponents of diversity maintain that different opinions provided by diverse groups lead to quality decisions (Cox, 1993; McLeod et al., 1992) as diverse teams are able to produce a wider range of solutions and decision criteria for strategic decisions.

\subsection{Top Management Team Diversity}

Carson et al., (2004) defined diversity as any attribute that humans are likely to tell themselves that another person is different from them while Miller et al. (1998) defined the Top Management Team as all executives who report to the Chief Executive Officer or Chief Operating Officer. Researchers have categorized diversity in different ways. One distinction is between diversity on observable or readily detectable attributes such as age and gender and diversity in respect to less visible or underlying attributes, such as education, functional backgrounds, and tenure in the organization, personality and values (Cumming et al., 1993; Tsui et at., 1992). 
The Top Management Team diversity discussed in the study is the extent to which the executive team is heterogeneous with respect to gender, age, academic qualifications, tenure, professional qualifications and functional back grounds. Simons et al. (1999) studied the same factors if TMT diversity with the exception of gender and professional qualifications. Diversity is an increasingly important factor in organizational life as organizations worldwide become more diverse in terms of gender, race, ethnicity, age and other characteristics (Shaw and Barrett-Power, 1998).

Hamrick and Mason, (1984) argued that TMT diversity would be best able to manage turbulent complex environments since team member differences may stimulate debate about the appropriate strategy, allow them to generate greater range of strategic alternatives and collectively better evaluate the feasibility of such alternatives. Bantel and Jackson (1989) concluded that when solving complex, non routine problems, groups are more effective when they comprise individuals with diverse skills, knowledge, abilities and perspectives. Pfeffer, (1983) found out that increases in TMT diversity enhances the organizations ability to acquire critical resources. Top Management Team diversity however comes with some challenges as initial conflict arises as the teams set norms (Carson et al., 2004). In order for teams to be efficient and effective, they must be able to reach a consensus regarding group decisions (Coll et. al., 2001).

\subsection{Organizational Performance}

Businesses today are faced with an increasingly competitive environment. To cope with this competition, organizations must be more adaptive. The performance of an organization can be measured in various ways which include qualitative and quantitative. One measure breaks down organization performance in to two broad ways. Firstly, some assess the stewardship of the top management or how efficient the organization utilizes its resources to produce a profit. Since the period considered is usually brief, these measures can be interpreted as indicators of how well fitted the organizational is to present conditions (Murray, 1989).

The second set of measure is based on the prevailing price of an organization's stock. The efficient markets hypothesis states that the stock price multiplied by the number of shares outstanding is the best available estimate of the true value of an organization (Murray, 1989). Some studies have shown that team heterogeneity had opposite effects on performance depending on the measure of heterogeneity selected (Wiersema, 1992).

Other studies especially in the service sector have measured performance based on employee productivity (Orlando, 2000). This is an important performance criterion in banks because human labor costs are high and is calculated as the logarithm of net income per employee per year. This measure reflects employee efforts disassociated from variations in product and capital markets (Jackson et al., 1987). Qualitative measures can be considered under outcomes which have affective (satisfaction, commitment, turnover, role conflict and group social integration), cognitive (innovation, range of perspective, number and quality of ideas) symbolic (behavior of lower level employees) and communication (communication with group members) consequences. Comparative performance can be measured in terms of an organization's current performance relative to other organizations in its industry in terms of product quality, employee morale, on time delivery, inventory management and employee productivity (Milliken and Martins,1996)

Hopkins and Hopkins (1997) used three measures in the financial performance of banks, namely, profits (or net income) as also used by Ansoff (1991), return on investment and return on shareholder equity (ROE). Bird (1991) also supports this measure. Deposit growth is another measure (Gup and Whitehead, 1989) which is unique to banking and related financial services industries. It is measured as the deposit percentage change in consumer deposits from one year to another. Dalaney and Huselid (1996) used both financial and non financial indicators. The financial indicators were a percentage growth in sales, labeled as sales growth and percentage profit margin labeled as profitability. They used public image and goodwill, quality of services and efficiency of operations as the non financial indicator.

The Top Management Team understands that organizational measurement system strongly affects the behaviors of management and employees. The TMT also understand that traditional financial measures like return on investment and earnings per share can give misleading signals for continuous improvement and innovation (Kaplan and Norton, 1992). As managers and academic researchers have tried to remedy the inadequacies in performance measurement systems, some have focused on making financial measures more relevant while others improve on operational measures such as cycle time and defect rates. Kaplan and Norton (1992) thus introduced the concept of a Balanced Scorecard as a basis for a strategic management system. This approach not only included financial and non financial aspects but also blended business strategies into management systems. 


\subsection{Quality Decisions}

Top Management Teams make strategic decisions and the quality of these decisions influence organization performance. Quality decisions are the ones that consider all issues deserving thought with respect to the situation. They depend on thoroughness. Researchers have found that group process conflict is multi dimensional in that cognitive conflict can improve decision quality, whereas effective conflict may weaken group relations by generating acrimony. Timely, high quality decisions that enjoy the understanding and acceptance of those who will implement them are the hallmark of an effective TMT. A team's cognitive capability is related to its cognitive diversity as diversity provides a resource of capabilities upon which the team can draw when making complex decisions.

Research findings indicate that TMT with diverse capabilities make more innovative and higher quality decisions than teams with less diverse capabilities ( Bantel and Jackson, 1989).However, the quality decisions depends heavily upon the process that the group actually employs. Rigorous debate of different and opposing positions produces a synthesis that is qualitatively superior to either of the initial positions. If group members sense that their own interest are at risk, they may undermine, sabotage or delay implementation of the decision. Top Management Teams make strategic decisions by combining their diverse cognitive capabilities with an interactive process resulting in the byproducts, quality decisions and satisfaction.

\subsection{Hypotheses}

$\mathbf{H}_{1}$ : Top Management Team diversity has effect on quality decisions.

$\mathbf{H}_{2}$ : Quality decisions have effect on organization performance.

\section{Methods}

The study was a cross sectional survey which targeted the top management team of all the commercial banks in Kenya and offered the opportunity to collect data across the different banks at the same time. The study between TMT diversity, quality decisions and organization performance seeks to establish the relationship between these variables and also the strength of these relationships.

\subsection{Test of Hypotheses}

The study had two objectives and two hypotheses which are addressed in this section. The first objective tested the effect of Top Management Team diversity on the quality decisions while the second one was to find out the effect of quality decisions on organizational performance. Simple regression analysis was used to determine the effect of TMT diversity on organizational performance, TMT diversity on quality decisions and on the organizational performance in hypotheses one, and two.

Hypothesis 1: Top Management Teams diversity has an effect on quality decisions

The first hypothesis sought to establish the relationship between TMT diversity and the quality decisions. The Top Management Team diversity under study was gender, age, tenure in the bank service, tenure at the Top management, academic, professional diversity and functional background while quality decisions consisted of determining the cause of major actions, generating alternatives to solve problems and final decisions and integration. Simple regression analysis was done in Table 1

Table 1 presents the results of the regression analysis, with $r=.474$ which shows a positive relationship between the factors making up TMT diversity and quality decisions. The value of $\mathrm{R}^{2}$ is .225 , meaning that factors making up TMT diversity can explain 22.5 percent of quality decisions. The rest, 77.5 percent is explained by other factors. The Durbin-Watson value is 1.843 , showing that the data is good for the analysis. The F ratio is .911 and is not significant meaning that the regression model does not predict the organization performance significantly well.

The results in Table 1 further show that tenure in the bank, has a significant effect on quality decisions with $\beta=.561$ at $\mathrm{p}<.05$. Other effect which are positive though not significant on quality decisions are professional qualifications diversity $(\beta=.123)$ and functional background $(\beta=.092)$. All the other factors of TMT diversity, namely, age, gender, academic qualifications, tenure at the top management have a negative effect on the quality decisions, which was not significant. We can therefore conclude that Tenure at the bank has a significant effect on quality decisions.

Hypothesis 2: Quality Decisions has an effect on Organizational Performance

The third hypothesis in the study was to test the effect of quality decisions on organization performance. This was to address the second objective which sought to find out how quality decisions affects organization performance. For the purpose of the study, quality decisions was made up of the factors taken into account when determining the cause of a major problem, when generating alternatives to solve problems and when arriving at the final decision. 
Organization performance was composed of the four perspectives of the balanced score card, namely, financial, customer, internal business processes and learning and growth.

The first analysis determined how the overall quality decisions affects the overall organization performance while a second analysis tested how the factors making up quality decisions affect each of the four factors making up organization performance using the balanced scorecard approach. The results are shown in Table 2 and Table 3 respectively

Table 2 shows the results of the regression analysis. The model shows that the value of $\mathrm{R}^{2}$ is .293 , an indication that factors making up quality decisions can explain 29 percent of organization performance. The rest, 71 percent is explained by other factors. The Durbin-Watson value is 1.920 , showing that the data is good for the analysis. The F ratio is 12.877 and is statistically significant at $\mathrm{p}<.001$ meaning that the regression model predicts the organization performance significantly well.

The beta coefficient at $\beta=.542$ at $p<.001$ shows that quality decisions contributes significantly to organization performance as per Table 2. This suggests that the quality decisions play a crucial role in determining the organization performance. Further analysis was undertaken to determine the effect of the factors making up quality decisions on the four perspectives of performance based on the balanced scorecard approach. The results of the findings are presented in Table 2.

\subsection{The Effect of Quality Decisions on Financial Perspective}

The results of the regression analysis of quality decisions against one factor of organization performance, financial perspective show the value of $\mathrm{R}^{2}$ is .135 , meaning that factors making up quality decisions can only explain 13.5 percent of financial performance. The rest, 86.5 percent is explained by other factors.

The Durbin-Watson value is 1.974 , showing that the data is good for the analysis. The F ratio is 1.505 with $\mathrm{p}=.234$ which is not significant meaning that the regression model does not predict the financial perspective based on the balanced scorecard significantly well.

Each coefficient value shows the degree each predictor affects the outcome, if the effects of all other predictors are held constant. All the factors of quality decisions have a positive effect on the financial performance with the exception of final decisions and decision integration. The beta coefficients show that determining the cause of a major problem has a positive effect on the financial perspective of performance $(\beta=.424)$ while final decisions and decision integration contributes negatively $(\beta=.-.185)$.

\subsection{The Effect of Quality Decisions on Customer Perspective}

The model summary in Table 3 shows that the value of $\mathrm{R}^{2}$ is .091 , meaning that factors making up quality decisions can only explain 9 percent of customer perspective. The other 91 percent is explained by other factors. The Durbin-Watson value is 1.533 , showing that the data is good for the analysis. The F ratio is .9 .62 with $\mathrm{p}=.424$ which is not significant meaning that the regression model does not predict the organization performance significantly well.

The same model shows that all the factors of quality decisions have a positive effect on the customer perspective, with generating alternatives being at $\beta=.163$. Since the combined effect on the equation from all the factors is positive, this means that the overall effect of quality decisions on the customer perspective is positive, though not significant.

\subsection{The Effect of Quality Decisions on Internal Business Processes Perspective}

The research results for the effect of quality decisions on the internal business processes perspective showed the value of $\mathrm{R}^{2}$ is .526 , meaning that factors making up quality decisions explain 53 percent of internal business processes. The rest, 47 percent is explained by other factors. The Durbin-Watson value is 1.819 , showing that the data is good for the analysis. The F ratio is 10.723 at $\mathrm{p}<.001$ which is statistically significant meaning that the regression model predicts the internal business processes perspective significantly well.

In addition, all the factors of quality decisions, except final decision and decision integration $(\beta=-.069)$ have a positive effect on the internal business processes. Determining the cause of a major problem has a positive effect which is also significant with $\beta=.524$ at $p<.001$ while generating alternatives to solve problems had a significant effect on internal business perspective of the balance scorecard with $\beta=.368$ and $p<.01$.

\subsection{The Effect of Quality Decisions on Learning and Growth Perspective}

Table 3 further shows the results of the regression analysis on the effect of quality decisions on the learning and growth perspective. The value of $\mathrm{R}^{2}$ is .407 , meaning that factors making up quality decisions can explain 41 percent 
of learning and growth. The rest, 59 percent is explained by other factors. The Durbin-Watson value is 2.374 showing that the data is good for the analysis. The F ratio is 6.624 with $\mathrm{p}<.001$ which is statistically significant meaning that the regression model predicts the learning and growth perspective significantly well.

The factors of quality decisions have a positive effect on learning and growth perspective of the Balanced scorecard approach with determining the cause of a major problem having significant effect with $\beta=.534$ at $p<.01$. Generating alternatives to solve problems and final decisions and decision integration also have positive though not significant effect on learning and growth perspective of the Balanced scorecard approach with $\beta=.018$ and $\beta=.148$ respectively.

In summary, the results in Table 3 indicate that quality decisions has a significant effect on the internal business processes perspective of the Balanced scorecard with $\mathrm{R}$ Squared $=.526$ at $\mathrm{p}<.01$ while the $\mathrm{F}$ factor is 10.723 . Further, the relationship between quality decisions and learning and growth perspectives was also significant with $\mathrm{R}$ Squares $=.407$ at $\mathrm{p}<.001$. The $\mathrm{F}$ factor was 6.624 which was significant. The effect of quality decisions on the financial and customer perspectives of performance was however not significant.

\subsection{The Effect of Quality Decisions on TMT Diversity and Organizational Performance}

The research results of the regression model show that quality decisions have an effect on the relationship between TMT diversity and organizational performance. The effect of Top Management Team diversity on organization performance had $\mathrm{r}=.100$ which improved to $\mathrm{r}=.565$ when quality decisions was introduced to the regression equation. The $\mathrm{R}^{2=} .010$ in the first model changed to $\mathrm{R}^{2=} .319$ which was significant at $\mathrm{p}<.001$ when the quality decisions was introduced into the equation, an improvement of .309. This indicates that the combined model can explain 31 percent of the outcome up from 1 percent given by the Top Management Team diversity alone, a percentage increase to prediction of 30 percent. The Durbin-Watson score was 1.953.

The $\mathrm{F}$ ratio in the first model which showed the effect of Top Management Team diversity on organization performance was $\mathrm{F}$ ratio $=.285$. When quality decisions was introduced to the regression equation the F-factor improved by 11.986 to 12.271 at $\mathrm{p}<.001$ which was statistically significant. These results indicate that quality decisions have a significant effect as an intervening variable in the relationship between Top Management Team diversity and organizational performance.

\section{Conclusion}

\subsection{TMT Diversity and Quality Decisions}

Hypothesis one was to determine the effect of TMT diversity on quality decisions. The study found out that tenure in the bank had a statistically significant effect on the quality decisions made by a diverse TMT in the commercial banks in Kenya. The other factors making up TMT diversity did not however have any significant effect on the quality decisions.

Diversity among the TMT is widely assumed to influence the quality decisions but empirical research on this linkage has been virtually limited. Past empirical research has shown that tenure can have both positive and negative effect on an organization. The common belief is that TMT members are naturally more comfortable with those they joined the banks with due to ease of identification or sense of belonging.

TMT with greater tenure are usually known to be more cohesive but less likely to change the status quo. Bantel and Jackson (1989) found a positive relationship between tenure and commitment to status quo. In a TMT composed of members who have worked for different periods, conflict is bound to happen as those who have worked for long feel that they have more institutional memory than those who have recently joined the team and as a result are committed to maintain things as they have always been. Status quo is likely to create a comfort zone, leaving no room for creativity and innovation which are critical components of the performance of banks and form the internal processes perspective of the balanced score card.

The findings of this study show that TMT with diverse tenure has a significant effect on the quality decisions. This means that diversity in tenure of the TMT is good for the performance of banks in Kenya. Banks should always ensure that they have a TMT which has worked for varying periods to draw the best. It is expected that those who have worked longer have valuable institutional memory while those who are newer bring in unique experiences in to the decision making process.

Generally, however, most of the factors which make up TMT do not have a significant effect on quality decisions. This can be interpreted to mean that a diverse TMT may not be cohesive enough and thus do not involve people directly impacted by the decision nor make extensive use of eternal experts. It may further be interpreted that the 
TMT which is diverse doesn't consider all the possible causes of problems, either due to limited communication among members or lack of cohesiveness. This confirms the findings by O'Reilly et al. (1989). Hambrick's (1994) concept of behavioral integration suggests that TMT diversity affects cohesion in that individuals assume that those who agree with them also like them and vis versa.

Further, this study confirms that TMT diversity affects cohesion, which was described by O'Reilly et al. (1989) as the extent to which TMT like one another and stick up for each other. Members of teams which are not cohesive are more likely to challenge opinions by their colleagues. They further encourage debate and initiate investigations designed to uncover flaws in the reasoning of their colleagues (Miller et al., 1989). Team members are known to value group membership to the extent where fear of membership loss results to conformity and unquestioned acceptance of ideas which compromises the quality decisions

Other empirical researchers have however argued that when there are many disagreements about a threat or an opportunity, TMT are aware of more issues, more ways of viewing each issue and more alternative courses of action (Bantel and Jackson, 1989). This results to in depth analyses and even hiring of experts to help solve the issues but if there is less disagreement, TMT is unlikely to consider the issues at depth. These arguments may result to reduced group think and more strategic options. Another argument that TMT diversity leads to quality decisions states that disagreement in strategic decisions leads to greater willingness to expand resources necessary for more analyses, consultations and discussions (Miller et al., 1989). The findings of this study indicate otherwise therefore we can conclude that TMT diversity does not have a significant effect quality decisions apart for tenure diversity is the bank which has a significant effect on quality decisions.

\subsection{Quality Decisions and Organizational Performance}

Hypothesis two was to determine the effect of quality decisions on organization performance. The study found out that the overall quality decisions (which consists of activities undertaken when determining the cause of a major problem, when generating alternatives to solve problems and when arriving at the final decision and decision integration) contributes significantly to the overall performance of the banks in Kenya.

The study also analysed the effect of the factors making up quality decisions on each of the four perspectives of organization performance based on the balanced scorecard approach, namely financial, customer, internal business processes and learning and growth. The study found out that some factors which make up quality decisions have a significant effect on some of the four perspective of organization performance based on the balanced scorecard. This means that the quality decisions play a crucial role in predicting the performance of banks in Kenya.

The study found that determining the cause of a major problem had a significant effect on the internal business processes, learning and growth and the financial perspectives of the balanced scorecard approach. Further generating alternatives to solve problems had a significant effect on the internal business processes. As stated above, determining the cause of a major problem had a significant effect on the internal business processes perspective of the balanced scorecard. The internal business processes perspective in the study was made up of efficient and automated business processes, high turnaround time on major banking services and higher level of innovation and creativity.

The findings indicate that banks which take time to determine the cause of a major problem had greater creativity, innovation and automation of their services. This was because the TMT involves those directly impacted by the decision and also considers all possible causes to a problem. The introduction of credit references bureaus have enhanced decision making by the TMT in banks. This allows sharing of credit information, and has brought efficiency in the credit system, brought down costs and made it easier for banks to lend individual credit track record.

On any given day, one will find bankers interacting with employees, students or even the community with the aim of offering them relevant and unique services. Such forums not only provide opportunities for opening new accounts but also empowering the communities. In 2011, Kenya witnessed banks appeal to citizens to help alleviate hunger in drought stricken parts of the country, thus enhancing their image among their customers.

Some banks have also been able to introduce some of the world's most secure banking software which includes, Pinnacle. Others have introduced advanced core banking infrastructure that allows SMS and internet banking. Further, the TMT in these banks make extensive use of external experts which in turn enhances efficiency and turnaround time of major banking services. The TMT in banks need to always consult those affected by decisions, provide the necessary resources and also make extensive use of consultants to enhance the levels of innovation, creativity and automation of their banking services. Many banks in Kenya have responded to their customer needs 
and launched Islamic banking products while others have consolidated banking products with insurance and introduced services like "bank assurance" and stockbrokerage.

The second finding was that determining the cause of a major problem had significant effect on learning and growth perspective. The factors which make up learning and growth perspective are high staff satisfaction level, ability to attract and retain staff and effective communication, both internally and externally. The study found that determining the cause of a major problem has a significant effect on the learning and growth perspective. In banks where the TMT involved those directly impacted by the decision have higher staff satisfaction and retention rate. This indicates that staff are motivated when they are involved and recognized, which in turn has a positive effect on their performance. This confirms that recognition contributes to motivation and to some extent, satisfaction. The TMT which consults their staff and provides all the required resources leads better communication and satisfaction level. Further, when all possible causes of a problem are considered in decision making, this is also likely to lead to staff involvement which results to higher satisfaction and enhanced communication both internally and externally.

The third finding indicated that determining the cause of a major problem had a significant effect on the financial perspective of the balanced scorecard. The financial perspective under study was made up of growth in customer deposits and return on shareholder equity. When divergent opinions are considered seriously and decisions taken are promptly implemented, this has a significant effect on the financial performance of the banks.

The final finding under this hypothesis was that when TMT in banks generate alternatives to solve problems, this has a statistically significant effect on internal business processes perspective. This means banks where the TMT hold brainstorming sessions during meetings and generate many options are better when it comes to creativity and innovation of banking services. This further indicates that TMT who share information about each option especially risks involved significantly contributed to the performance of their internal business processes.

Banks in which the TMT made extensive use of historical data also had more efficient banking services and created of better products. Automation of banking services is an expensive and complicated task. The banks which hire experts for complex activities also had higher automation levels which in turn lead to enhanced efficiency and high turnaround time on major banking services. Some foreign owned banks in Kenya have been utilizing their global expertise in the corporate and retail arena to win over Kenyans of foreign origin or expatriates working in the country so that they can enjoy advance cash transfers, among other products. Others have used their foreign connections to have some formidable accounts with multinational organizations. Banks therefore which encourage deliberate brainstorming sessions, sharing information, use of experts and historical data were found to be more competitive in terms of creativity, innovation and automation of their services.

As noted from the discussion above, quality decisions significantly contribute to the learning and growth perspectives and the internal business process. Quality decisions does not however have a significant and direct impact on the customer aspects of performance in the banking sector in Kenya which consists of growth in the market share response to customer complaints and satisfaction of the customers.

This implies that serious brainstorming of issue to come up with quality decisions has no effect on customer satisfaction. This can be interpreted to mean that the customer in the banking sector in Kenya today is very dynamic and sophisticated. Their needs are identified and addressed through other means not by a TMT sitting, brainstorming and deliberating on them in a boardroom.

\subsection{TMT Diversity, Quality Decisions and Organizational Performance}

In some past studies, TMT diversity was related to organization performance, without considering the mediating effect of process variables. Diversity effects on firm outcomes may however be too weak to be detected consistently and more so in cross sectional studies (Miller et al., 1998). As a result, this study used the quality decisions to determine the intervening effect on the relationship between TMT diversity and organization performance. Simons (1999) found that decision comprehensiveness intervenes on the relationship if TMT diversity and organization performance while moderated by debate. Some researchers who have studied comprehensiveness of strategic decisions have found that it has an impact on organizations profitability. Miller et al. (1998) suggested positive effects for organizations in turbulent environments while there is no effect in organizations in stable environments. Some researchers also have strong beliefs that a diverse TMT compromises the quality decisions.

The study found that quality decisions have a significant effect on organization performance. When TMT diversity was combined with the quality decisions, the effect on organization performance was statistically significant meaning that quality decisions has an intervening effect on the relationship between TMT diversity and organization performance. Many researchers' believe that diverse teams use their experiences and different backgrounds to 
communicate to each other. Researchers have suggested that this differentiation may lead to communication failure. As a result, a small group of the TMT may decide to address strategic issues quietly without consulting the larger team (Miller et at., 1989).

From the findings of this study, organizations need to encourage diverse TMT to have meetings which identify the causes of major problems as such forums provide an opportunity for generating many options through the brainstorming process. Further, it allows information sharing and allocation of the desired resources. During their meeting, the diverse TMT members are likely to enhance communication and come up with new ideas to improve the bank services. The banking sector in Kenya has expanded its networks very rapidly within the last four years. Some banks have used the expansion strategy to transform from small time players to large one- stop financial institutions. One bank is known to have opened 35 new branches across Kenya in 2008, using the expansion strategy to meet the customer demands. Several banks have recently expanded to neighboring countries including Southern Sudan, Tanzania, Uganda and Rwanda to enhance their revenue base

In the final analysis, the use of quality decisions was found to have a significant effect on the relationship between TMT diversity and performance of organizations. We can further conclude that different moderating variables have varying influence on the relationship between TMT diversity and the quality decisions and TMT diversity and organization performance. Further implementing policies to support diversity management has better influence on the quality decisions and performance than banks which have not put in place such strategies.

\section{Implications of the Study on Theory, Policy and Practice}

The current study confirms the mixed findings on the relationship between TMT diversity and performance. It also gives consistent negative effect of observable attributes, namely age and gender on quality decisions and performance. It confirms earlier researches that biases and discrimination on easily observable attributes may still be contributing negatively to organization performance.

On theory, the study shows that TMT diversity has no significant effect on quality decisions. The study further confirms some earlier findings that TMT diversity does not have a significant effect on organization performance. Further, the study contributes to theory in that diversity in functional background has a significant effect on the quality decisions of the TMT. The quality decisions also has a significant effect on the internal business processes perspective and learning and growth perspectives of the balanced scorecard approach of organizational performance.

As stated earlier, the government of Kenya is committed to have at least 30 percent presentation of any gender in public recruitments, promotions and appointments to all decision making level through gender mainstreaming in government policies, plans, budgets and programmes. What is clear is that gender diversity does not contribute significantly to the quality decisions. These programmes should therefore be for affirmative action not necessarily for increase in output. Further, on its own, age diversity does not have any significant contribution to quality decisions or performance. Diversity in the workplace should however be encouraged for good governance, equity and fair distribution not necessarily because of any expected increased outcome.

However, when the minorities are involved in decisions affecting them, when relevant information is shared, then this enhances the quality decisions and the performance of the diverse bank teams. Diversity management strategies are not widely applied in Kenya. In fact, in some countries, like South Africa and the United States of America, laws have been passed to ensure that the interests of the minorities are well taken care of. Legislation on representation of age diversity should be encouraged in Kenya.

This study further bears significant implications for those responsible for the composition of the TMT and for organization performance. The study clearly confirms earlier research findings that TMT diversity has no significant effect the performance of organizations. In particular, the study identifies gender diversity and age diversity as having negative effects on quality decisions and organization performance. This implies that recruiting more of one gender to create a balance has a negative impact on the performance of organizations.

The study gives input in that gender diversity is not expected to enhance the quality decisions in the organizations but the same will be good for affirmative action. Diverse ages too at the top have a negative effect on performance as people view the world based on their socialization and environments. High diversity in age of the top managers needs to be discouraged while composing Top Management Teams as if affects their performance negatively.

Further, the study established that out of the seven factors of diversity under study, tenure with the bank had the highest positive effect on both performance and the quality decisions. This finding is very critical to the human resources managers to ensure a mix of years worked by the TMT which contributes to the performance of banks. The HR managers can ensure that the TMT team is composed of members who have worked for diverse periods so that 
banks can continually ensure a mix in experience at the top. The new members to the TMT may inject fresh ideas to the bank like advanced technology while drawing from the experiences of those who have been in the banks longer.

The study also emphasizes the importance of how quality decisions affects performance of banks positively. Policy and decision makers need to involve those who are impacted by decisions and also take time to determine the causes of major problems. In addition, the need to brain storm, generate many options, engage experts and make use of historical data add value in coming up with quality decisions.

While making the final decisions, TMT need to make contingency plans, compare several alternatives and promptly implement decisions in order to enhance the performance of the banks. The Constitution of Kenya, 2010 recognizes the need to involve those who are affected by decision in the decision making process. The benefits of this critical need are confirmed in this study.

This research also serves as a reference point for those studying the relationship between TMT diversity, quality decisions and organization performance. Other researchers can test other moderators to this relationship to find out which ones have the most significant effect. Decision makers in organizations and more so banks, can be guided by the finding of the study while recruiting TMT's and also while developing policies which aim at retaining and maintaining their employees.

\section{References}

Ansoff, H. I. (1991). Critique of Henry Mintzberg's 'the design school: Reconsidering the basic premises of strategic management. Strategic Management Journal, 12(6), 449-461. http://dx.doi.org/10.1002/smj.4250120605

Bantel, K.A., \& Jackson, S. E. (1989). Top Management and innovations in Banking: Does the composition of Top Management make a difference? Strategic Management Journal, 10, 107-124. http://dx.doi.org/10.1002/smj.4250100709

Bird, A. (1991). A 1990s twist of strategic planning. Bankers Magazine, 66-69.

Carson, M.C., Mosley, D. C., \& Boyar, S.L. (2004). Performance gains through diverse top team management. Team Performance Management, 10, 21-126. http://dx.doi.org/10.1108/13527590410556845

Coll Sambrhanya R.B., \& Tucci L.A. (2001). Top Management Team composition, corporate ideology and organization performance. Mat Turter, 41(2), 109-129.

Cox, T.H. (1993). Cultural diversity in organizations: Theory, research and practice. Berrett-Koehler, SA Francisco, CA.

Cox, T. H., Lolel S. A., \& Mcleod, P.L. (1991). Effects of ethnic group cultural differences on cooperative and competitive behavior on a group task.

Government of Kenya (2007). Vision 2030, Ministry of planning and National Development and the National Economic and Social Council (NESC), Office of the President.

Gup, B.E., \& Whitehead, D.D. (1989). Strategic planning in banks: Does it pay? Long range planning. http://dx.doi.org/10.1016/0024-6301(89)90060-5

Hambrick, D.C. (1994). Top Management groups: A conceptual integration and reconsideration of the team label.

Hambrick, D.C., \& Mason, P.A. (1984). Upper echelons: the organization as a reflection of its top managers. Academy of management Review, 9, 193-206.

Hoffman, L.R., \& Maier, N.R.F (1961). Quality and acceptance of problem solutions by members of homogeneous and heterogeneous groups. Journal of Abnormal and Social Psychology, 62, 401-407. http://dx.doi.org/10.1037/h0044025

Hopkins W.E., \& Hopkins, S.A. (1997). Strategic planning- financial performance relations in banks. A causal examination.

Jackson, S.E., Brett, J.F., Sessa, V.I., Cooper, D.M., Julin, J.A., \& Peyronnin, K. (1991). Some differences make a difference: Individual dissimilarity and group heterogeneity as correlates of recruitment, promotions, and turnover. Journal of Applied Psychology, 76, 675-689. http://dx.doi.org/10.1037/0021-9010.76.5.675

Kaplan, R.S., \& Norton, D.P. (1992). The Balanced Scorecard measure that drives performance. Harvard Business Review Jan-Feb. 
Miller, C.C., Linda M. B., \& William H.G (1998). Cognitive diversity among Upper-Echelon Executives: Implications for strategic decision processes. Academy of Management Journal, 19, 39-58.

Miller, D. (1998). Relating Porter's business strategies to environment and structure: Analysis and performance implications. Academy of Management Journal, 37, 280-308.

Milliken F.J., \& Martins L.L. (1996). Searching for common threads: Understanding the multiple effects of diversity on organizational groups. Academy of Management Review, 21, 402-433.

Murray, A. (1989). Top management group heterogeneity and organization performance. Strategic Management Journal, 10, 125-141. http://dx.doi.org/10.1002/smj.4250100710

Pfeffer, J. (1983). Organizational Democracy, 3, 1-52. Greenwich CT JAI Press.

Shaw, J. B., \& Barrett-Power, E. (1998). The effects of diversity on small work group processes and Performance. Human Relations, 51(10), 1307-1325. http://dx.doi.org/10.1177/001872679805101005

Simons, T., Pelled, L.H., \& K.A Smith. (1999). Making use of difference: Diversity, debate and decision comprehensiveness in Top Management Teams. Academy of Management Journal, 42(6), 662-673. http://dx.doi.org/10.2307/256987

Tsui A. S., Egan T. D., \& O'Reilly C. A. (1992). Being different: Relational demography and organizational attachment. Administrative Science Quarterly, 37, 549- 579. http://dx.doi.org/10.2307/2393472

Wiersema M. F., \& Bantel, K. A. (1992). Top Management team demography and corporate strategic change. Academy of Management Journal, 35, 91-121. http://dx.doi.org/10.2307/256474

Zenger, T. R., \& Lawrence, B. S. (1989). Organizational demography: The differential effects of age and tenure distribution on technical communication.

Table 1. TMT diversity and quality decisions

\begin{tabular}{|c|c|c|c|c|}
\hline \multirow[t]{2}{*}{ Model } & & \multicolumn{2}{|c|}{ Unstandardized Coefficients } & \multirow{2}{*}{$\begin{array}{l}\text { Standardized } \\
\text { Coefficients } \\
\text { Beta } \\
\end{array}$} \\
\hline & & $\mathrm{B}$ & Std. Error & \\
\hline & (Constant) & 10.510 & 1.314 & \\
\hline & Gender Diversity & -.438 & 2.059 & -.043 \\
\hline & Age Diversity & -.383 & .792 & -.125 \\
\hline & Tenure diversity in bank service & 1.231 & .558 & $.561^{*}$ \\
\hline & Tenure diversity at top management & -.778 & .735 & -.263 \\
\hline & Academic diversity & -.021 & .647 & -.007 \\
\hline & Professional qualifications diversity & 1.037 & 2.062 & .123 \\
\hline & Functional backgrounds diversity & .743 & 2.038 & .092 \\
\hline \multicolumn{5}{|c|}{ Dependent Variable: QUALITY DECISIONS } \\
\hline $\begin{array}{l}r=474 \\
R \text { Squar } \\
F=.911\end{array}$ & $\mathrm{ed}=.225$ & & Vatson $=1.8$ & \\
\hline
\end{tabular}

${ }^{*} \mathrm{P}<.05$

Table 2. Quality decisions and organizational performance

\begin{tabular}{|c|c|c|c|}
\hline \multirow[t]{2}{*}{ Model } & \multicolumn{3}{|c|}{ OVERALL ORGANIZATION PERFORMANCE } \\
\hline & $\mathrm{B}$ & Std. Error & Beta \\
\hline (Constant) & 14.894 & 6.547 & \\
\hline QUALITY DECISIONS & 2.015 & .562 & $.542^{* * *}$ \\
\hline \multicolumn{4}{|c|}{$\begin{array}{l}\text { R Squared }=.293 \text {, Change in R Squared }=.293, \mathrm{~F} \text { Change }=12.877 \text {, } \\
\text { Durbin-Watson }=1.920\end{array}$} \\
\hline
\end{tabular}


Table 3. Quality decisions and perspectives of organizational performance

\begin{tabular}{|c|c|c|c|c|c|c|c|c|c|c|c|c|}
\hline \multirow[t]{2}{*}{$\begin{array}{l}\text { Independent } \\
\text { Variables }\end{array}$} & \multicolumn{3}{|c|}{ Financial Perspective } & \multicolumn{3}{|c|}{ Customer Perspective } & \multicolumn{3}{|c|}{ IBP Perspective } & \multicolumn{3}{|c|}{$\begin{array}{l}\text { Learning and Growth } \\
\text { Perspective }\end{array}$} \\
\hline & $B$ & $S E$ & $B$ & $B$ & $S E$ & $\beta$ & $B$ & $S E$ & $B$ & $B$ & $S E$ & $\beta$ \\
\hline (Constant) & 5.530 & 2.645 & & 7.410 & 2.717 & & .727 & 1.612 & & 4.249 & 2.228 & \\
\hline $\begin{array}{l}\text { Determining } \\
\text { the cause of a } \\
\text { major } \\
\text { problems }\end{array}$ & .573 & .295 & ${ }_{*}^{.424}$ & .118 & .303 & .087 & .583 & .180 & $.524^{* *}$ & .733 & .249 & $.534^{* *}$ \\
\hline $\begin{array}{l}\text { Generating } \\
\text { alternatives to } \\
\text { solve } \\
\text { problems }\end{array}$ & .035 & .200 & .035 & .165 & .205 & .163 & .305 & .122 & $.368^{* *}$ & .018 & .168 & .018 \\
\hline $\begin{array}{l}\text { Final decision } \\
\text { and decision } \\
\text { integration }\end{array}$ & -.154 & .178 & $\begin{array}{l}-.18 \\
5\end{array}$ & .102 & .183 & .122 & -.047 & .109 & -.069 & .125 & .150 & .148 \\
\hline $\begin{array}{l}\text { Model } \\
\text { Summary } \\
\text { results }\end{array}$ & $\begin{array}{l}r=.36 \\
R \text { Squ } \\
\text { F Cha } \\
\text { Durbi } \\
\text { Watso }\end{array}$ & $\begin{array}{l}\mathrm{e}=.135 \\
\mathrm{ge}=1.50 \\
=1.974\end{array}$ & & $\begin{array}{l}\mathrm{r}=.30 \\
\mathrm{R} \text { Squ } \\
\mathrm{F} \text { Cha } \\
\text { Durbi } \\
\text { Watso }\end{array}$ & $\begin{array}{l}=.091 \\
=.962 \\
1.533\end{array}$ & & $\begin{array}{l}\mathrm{r}=.72 \\
\mathrm{R} \mathrm{Squ} \\
\mathrm{F} \text { Cha } \\
\text { Durbi } \\
\text { Watso }\end{array}$ & $\begin{array}{l}\mathrm{e}=.526 \\
\mathrm{e}=10.7 \\
=1.819\end{array}$ & & $\begin{array}{l}\mathrm{r}=.63 \\
\mathrm{R} \mathrm{Squ} \\
\mathrm{F} \text { Cha } \\
\text { Durbir } \\
\text { Watso }\end{array}$ & $\begin{array}{l}\mathrm{e}=.407 \\
\mathrm{e}=6.62 \\
=2.374\end{array}$ & \\
\hline
\end{tabular}

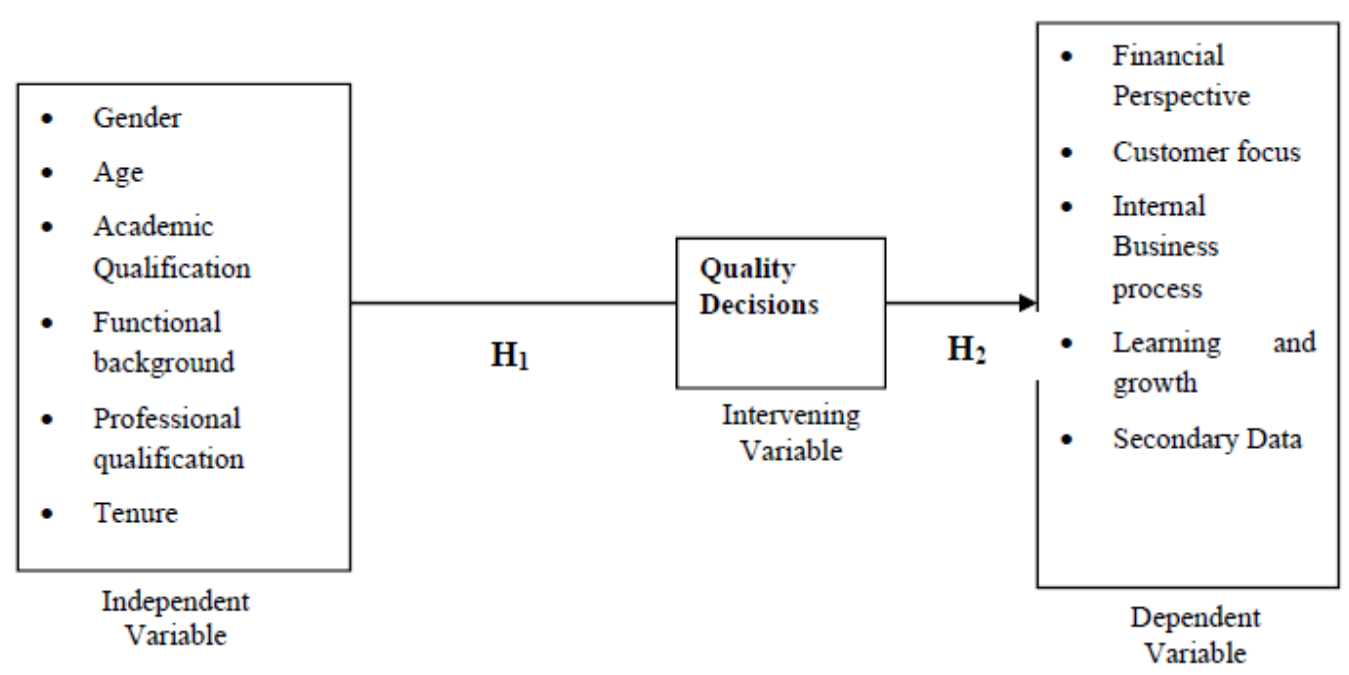

Figure 1. Conceptual model 